\title{
BIOTRANSFORMATIONS OF RIFAMYCINS: PROCESS POSSIBILITIES
}

\author{
U. C. BANERJEE, ${ }^{*}$ B. SAXENA* and Y. CHISTI $\dagger$ \\ *Biochemical Engineering Research and Process Development Centre, Institute of \\ Microbial Technology, P.O. Box 1304, Sector 39A, Chandigarh 160, 014, India \\ tDepartment of Chemical Engineering, University of Waterloo, Waterloo, Ontario, \\ Canada N2L 3G1
}

\begin{abstract}
Rifampicin, an important antibiotic, is manufactured by chemical conversion of rifamycin $S$ which is obtained by the chemical modification of rifamycin B. Rifamycin B is a product of Nocardia mediterranei fermentations. The chemical conversion of rifamycin $\mathrm{B}$ to rifamycin $S$ has many disadvantages: Strong acidic conditions are required, heavy foam formation accompanies transformation and the yields are low. This review highlights the developments in alternative, biochemical transformations using enzymes and cells; the main focus is on transformations carried out by rifamycin oxidase.
\end{abstract}

\section{Key Words}

Rifamycin antibiotics, biotransformation, rifamycin oxidase, Monocillium sp., Humicola sp., Curvularia lunata.

\section{Introduction}

Chemical or biochemical transformation of naturally produced antibiotics can potentially be used to alter some of the characteristics of the natural substances. Changes in antimicrobial activity, spectrum of action, oral absorption, toxicity and allergenic responses may be achieved. A commercially used example of such a transformation is the conversion of penicillins (predominantly benzyl penicillin) to 
6-amino penicillanic acid, 6-APA, which is a precursor for other semi-synthetic penicillins. The enzyme penicillin acylase produced by Escherichia coli, other bacteria and fungi [1], is the basis of this conversion which involves selective hydrolysis of the amide bond in the penicillin side-chain.

Rifampicin, a powerful antibiotic against certain important diseases, is currently produced by a scheme utilising fermentation followed by chemical conversion: The relatively inactive precursor, rifamycin B, is produced by Nocardia mediterrane in submerged culture; it is converted to the active rifamycin $\mathrm{S}$ in a chemical process. The low $\mathrm{pH}$ requirements of the chemical conversion necessitate expensive acid-resistant equipment, the yields are low and excessive foam formation causes operational problems. As a result, rifampicin is one of the more expensive antibiotics. In view of the shortcomings of the chemical conversion step, alternative biotransformations of rifamycin $B$ to $S$ have been investigated $[2,3]$. Here we review these biotransformation methods based in several forms of biocatalysts: immobilized enzymes, growing and resting whole cells, and pretreated cells.

\section{Rifamycins}

From the culture filtrate of the original strain of $N$. mediterranei, seven metabolites (rifamycins A-E, G and $\mathrm{Y}$ ) were isolated [4, 5-7]. The structures of these natural rifamycins are shown in Figure 1 [8]. Of these, rifamycin $\mathrm{B}$ was chosen for development because of its stability, ease of purification and solubility at physiological pH's. Addition of barbiturates to the fermentation media was used to dramatically alter the product mix, favouring the formation of rifamycin $\mathrm{B}$, and hence establishing a practical method for its production $[9,10]$. Rifamycin B was demonstrated to be microbiologically inactive [11]; its apparent activity depended on its transformation into active products in test cultures or in body fluids. The transformation products (rifamycin $\mathrm{O}, \mathrm{SV}$ and $\mathrm{S}$ ) were isolated and found to be microbiologically very active. Due to its good in-vivo activity, tolerability and solubility properties, rifamycin SV was chosen for further studies. Rifamycin SV has been marketed in several countries for the treatment of infections from gram- 


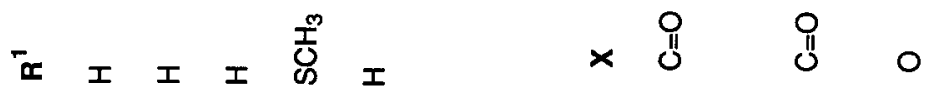

๔ I

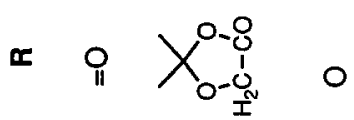

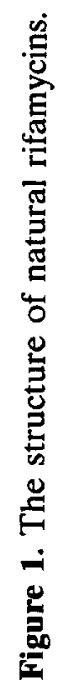

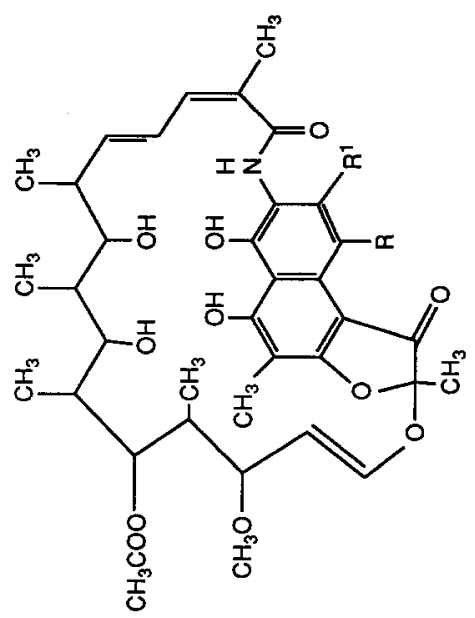

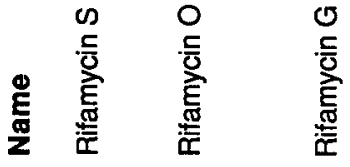

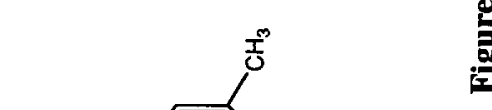


positive bacteria, but it is poor in anti-tuberculotic activity. Hundreds of compounds were synthesized from rifamycin B, O and $\mathrm{S}$ with the aim of obtaining a product superior to rifamycin SV in at least two respects: activity by oral administration and greater efficacy in curing tuberculosis. These goals were attained with rifampicin which is now widely used for the treatment of leprosy, tuberculosis and several other infectious diseases [12]. Rifampicin is at present also used in several other infections, notably in severe infections by Staphylococci resistant to $\beta$-lactam antibiotics and infections caused by intracellular bacteria.

Rifamycin SV, rifamide and rifampicin are the rifamycin group of antibiotics which are industrially produced and used as drugs. Their minimum inhibitory concentration (MIC) values against a range of organisms are given in Table 1 [11]. Rifampicin is also effective against trachoma and inhibits certain viruses and experimental tumours. Other semi-synthetic rifamycins are 27-demethyl-rifamycin SV and, 25-deacetyl and 27-demethyl rifamycin B. Rifamycin S is of considerable

Table 1. Minimum Inhibitory Concentrations of Rifamycin Group of Antibiotics

\begin{tabular}{|c|c|c|c|}
\hline \multirow[b]{2}{*}{ Infecting Microorganism } & \multicolumn{3}{|c|}{ Minimum Inhibitory Concentration $(\mu \mathrm{g} / \mathrm{mL})$} \\
\hline & Rifamycin SV & Rifamide & Rifampicin \\
\hline Staphylococcus aureus ATCC 6538 & 0.005 & 0.01 & 0.002 \\
\hline Streptococcus faecalis ATCC 10541 & 0.05 & 0.1 & 0.01 \\
\hline Streptococcus pyogenes C 203 & 0.002 & 0.01 & 0.02 \\
\hline Diplococcus pneumoniae XXLIIL & 0.025 & 0.02 & 0.01 \\
\hline Neisseria gonorrhoeae ATCC 9826 & - & 0.005 & 0.02 \\
\hline Haemophilus influenzae ATCC 9334 & - & - & 0.02 \\
\hline Escherichia coli (McLeod) & 50 & 10 & 1 \\
\hline Klebsiella pneumoniae ATCC 10031 & 25 & 20 & 5 \\
\hline Proteus vulgaris X 19 & 25 & 20 & 5 \\
\hline Salmonella typhi & 100 & 20 & 5 \\
\hline Pseudomonas aeruginosa & 50 & 50 & 10 \\
\hline Mycobacterium tuberculosis $\mathrm{H}_{37} \mathrm{Rv}$ & 0.05 & 0.2 & 0.5 \\
\hline
\end{tabular}

Based on Sensi et al. [11]. 
economic importance because it is a precursor for the majority of semi-synthetic rifamycin antibiotics. Although, it is possible to produce the biologically active rifamycin $\mathrm{S}$ by fermentation from a blocked mutant, its yield is low compared to that of rifamycin B. Addition of sodium diethyl barbiturate to the fermentation medium results essentially in the formation of a single product, rifamycin $B$.

\section{Biotransformation of Rifamycins}

Biotransformation of rifamycin was first reported by Lancini et al.[13] who found that washed mycelia of Nocardia mediterranei could convert rifamycin B to rifamycin Y. It was further shown that rifamycin Y was not produced by "ex novo" synthesis, but originated from rifamycin $\mathrm{B}$; this transformation did not require the addition of diethyl barbituric acid. This work provided strong evidence that rifamycin B was the natural precursor of rifamycin Y. In 1969 biotransformation of rifamycin $\mathrm{S}$ to rifamycin $\mathrm{B}$ and rifamycin $\mathrm{L}$ by washed cells of $N$. mediterranei was reported [14]. Acetylation (rifamycin $S$ to rifamycin B) and esterification (rifamycin $\mathrm{S}$ to rifamycin $\mathrm{L}$ ) reactions were involved. Based on these observations Lancini et al. [14] proposed that in N. mediterranei fermentations, rifamycin S or its reduced form (rifamycin SV) is the first microbiologically active product of the biosynthetic pathway, and is the precursor of rifamycins B and L. In the same year Lancini and Hengeller noted that $N$. mediterranei also deacetylates rifamycin B [15]. A little later, White et al. discovered that the washed mycelium from a rifamycin $\mathrm{B}$ producing strain of $N$. mediterranei transformed rifamycin $\mathrm{W}$ into rifamycin B [16]. This biotransformation proved that the mycelia of $N$. mediterranei are capable of carrying out the necessary modifications, i.e., removal of methyl group and introduction of oxygen molecule, to transform the common progenitor into rifamycin S. Lancini et al. demonstrated that washed cells of $N$. mediterranei transformed the quinone ring of rifamycin $S$ into pyrone ring of rifamycin G [7]. Later, Ghisalba et al. showed that a strain of $N$. mediterranei N813 (rifamycin B producer) partially transformed protorifamycin I to protorifamycin $\mathrm{W}$ [17]. The formation of a small amount of rifamycin B from protorifamycin I could also be detected [17]. 

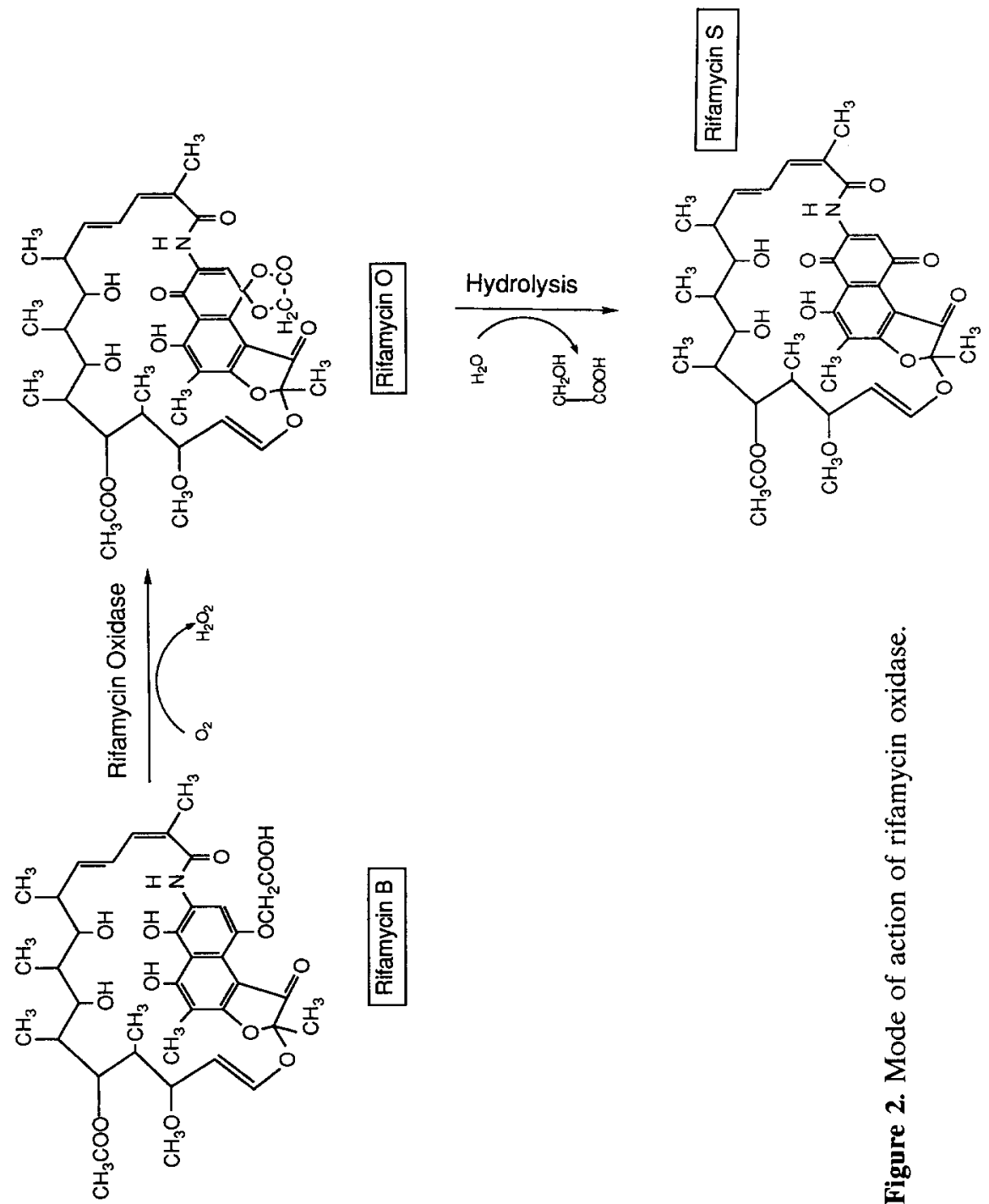

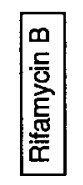

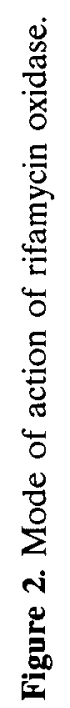


More recently, Schupp et al. of Ciba-Geigy determined that the washed mycelia of a recombinant strain of $N$. mediterranei R-21 transformed $50 \%$ of the added rifamycin $S$ to rifamycin B in 24 hours and $90 \%$ in 48 hours [18]. No other transformation of rifamycins was detectable under the conditions used. Ghislba et $a l$. were able to coax permeabilized cells of $N$. mediterranei and $E$. coli into transforming rifamycin S to rifamycin SV [19]. This transformation was NADH dependent, but was not specific for the rifamycin biosynthetic pathway [19]. The reduction was probably due to the reducing conditions of the cells.

The above cited biotransformation studies were carried out to elucidate the biosynthetic pathways of rifamycins.

\section{Bioprocesses for rifamycin S production}

Possible advantages of biotransformation over the conventional chemical means prompted researchers to look for new microbial strains with rifamycin B transforming activity. In 1983 the first real biotransformation of inactive rifamycin $\mathrm{B}$ to the active S-form was reported by Han et al. [2]. They isolated two fungi imperfecti, Humicola sp. (ATCC 20620) and Monocillium sp. (ATCC 20621), which could catalyze the conversion of rifamycin $B$ to rifamycin $O$ and on to rifamycin $\mathrm{S}$, which is the reverse reaction of rifamycin $\mathrm{B}$ biosynthesis. The enzyme from Monocillium sp. catalysed the oxidative reaction of rifamycin B to rifamycin $O$ [2]. The identification of the reaction products suggested that the reaction proceeded by oxidative cyclization of rifamycin $\mathrm{B}$ to give rifamycin $\mathrm{O}$, which on spontaneous hydrolysis, gave rifamycin $S$ in neutral aqueous solution. The characterization of the enzyme was different as compared with that of other polyphenol oxidases such as laccase. They classified this enzyme into a sub group EC.1.10.3.6 with a trivial name rifamycin oxidase [2].

The mode of action of rifamycin oxidase, as presented in Figure 2, was suggested [2]. In the two-step transformation reaction, one mole of rifamycin $B$ reacts with one mole of oxygen to produce one mole each of rifamycin $\mathrm{O}$ and hydrogen peroxide. Further hydrolysis of one mole of rifamycin $\mathrm{O}$ produces one mole each of rifamycin $\mathrm{S}$ and glycolic acid. From the stoichiometry it is also 


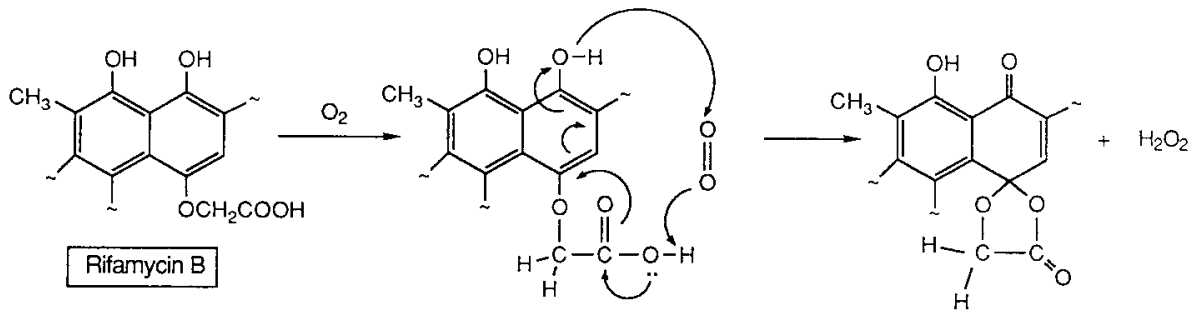

Rifamycin O

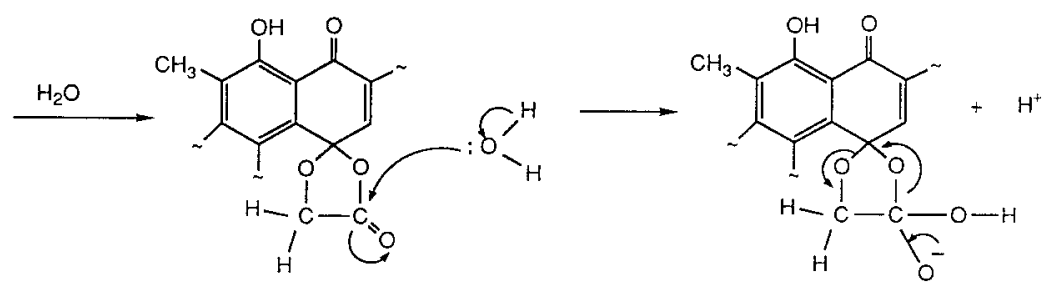<smiles>Cc1c(O)c2c(c(C)c1F)C(=O)C=C([18F])C2=O</smiles>

Rifamycin S

Glycolic acid

Figure 3. The reaction mechanism for transformation of rifamycin B to rifamycin S. 
known that $100 \mathrm{~g}$ of rifamycin B yields $92 \mathrm{~g}$ of rifamycin $\mathrm{S}$. From the action of rifamycin oxidase on rifamycin $B$, it seems that substituted hydroquinone moiety of rifamycin B is converted to quinone form of rifamycin B, i.e., to rifamycin S. The proposed organic reaction mechanism of this transformation is shown in Figure 3.

The same group of workers also published the isolation procedure of Monocillium sp. and its morphological and culture characteristics [20]. They further demonstrated that rifamycin $\mathrm{S}$ can be prepared in high yield by microbial transformation of rifamycin B [20].

In 1989 Vohra et al. reported a highly active extracellular rifamycin oxidase from Curvularia lunata var aeria [3]. This enzyme could effectively transform rifamycin B to $\mathrm{S}$. The time course of this conversion, monitored by HPLC [21], showed rapid consumption of rifamycin $\mathrm{B}$, with $90 \%$ of it disappearing within the first twenty minutes of incubation. The production of rifamycin $\mathrm{O}$ was correspondingly fast and it underwent spontaneous hydrolysis to rifamycin $\mathrm{S}$. Within an hour all the rifamycin $\mathrm{B}$ was converted to rifamycin $\mathrm{O}$ and most of the latter was hydrolysed to rifamycin $\mathrm{S}$.

\section{Production of rifamycin oxidase}

In order to increase the intracellular rifamycin oxidase production by Humicola sp., biochemical engineering studies were conducted by Kim et al. [22]. The maximum specific enzyme activity in fermentations without $\mathrm{pH}$ control was reported to be $9.5 \mathrm{IU} / \mathrm{g}$ dry cell, and $15 \mathrm{IU} / \mathrm{g}$ dry cell for cells cultured at controlled $\mathrm{pH}$ of 8.0 [22]. Rifamycin oxidase production was accompanied by biomass growth [22]. Antifoam (Neorin 202) concentrations lower than $1 \%(\mathrm{v} / \mathrm{v}$ ) did not have any significant effect on cell growth or on enzyme productivity [22]. $\mathrm{pH}$ control enhanced cell growth as well as enzyme production. The maximum specific cell growth rate was $0.24 \mathrm{~h}^{-1}$ at a constant $\mathrm{pH} 7.0$, but it was only $0.19 \mathrm{~h}^{-1}$ in absence of $\mathrm{pH}$ control. Highest specific enzyme activity and productivity were observed at $\mathrm{pH}$ 8.0. No significant repression of enzyme production by high glucose concentrations was apparent up to $60 \mathrm{~g} / \mathrm{L}$ glucose [22]. At this glucose 
concentration, 15 IU of enzyme activity per gram dry cell weight were obtained (with $\mathrm{pH}$ control) and total enzyme production was $300 \mathrm{IU} / \mathrm{L}$.

The effects of different carbon and nitrogen sources and of environmental factors $(\mathrm{pH}$, temperature) on the production of rifamycin oxidase by $C$. lunata have been studied [23, 24]. Carboxymethylcellulose, yeast extract and peptone (1\% $\mathrm{w} / \mathrm{v}$, each) and ammonium sulphate ( $0.04 \%$ nitrogen content) were determined to be the best combination for maximum rifamycin oxidase production [24]. Other synthetic media were also tested, but no growth or enzyme production occurred in those media [23]. When carboxymethylcellulose was used as a carbon source, the organism ( $C$. lunata) formed mycelial type of growth rather than pellet type [23]. With other substrates, pellet type of growth prevailed [23]. Mycelial growth always yielded higher enzyme activity [24]. Enzyme activity was reduced under conditions which led to intracellular black pigment production. $C$. lunata could produce high amounts of extracellular rifamycin oxidase within 40-50 hours of fermentation. The enzyme yield was found to be $3400 \mathrm{IU} / \mathrm{g}$ (dry weight) cell mass. The $C$. lunata rifamycin oxidase being an extracellular enzyme requires simpler downstream processing relative to the enzyme from Humicola sp. Filtered broths of $C$. lunata can be used for the transformation reaction. The intracellular enzyme from the Humicola sp. may require cell disruption for extraction of enzyme activity. Alternatively, delipidation of Humicola sp. may be used to reduce the diffusional resistances during the transformation reactions while fixing the enzyme within the cells. Compared to Humicola sp. enzyme, the enzyme from C. lunata has an important advantage for industrial applications. So far there is no literature on the production of rifamycin oxidase by Monocillium sp.

\section{Characteristics of rifamycin oxidase}

The characteristics of rifamycin oxidase from Humicola sp. are different from that of Monocillium sp. The enzymes differ noticeably in optimum $\mathrm{pH}$, temperature, degree of inhibition by substrates and in activities toward $p$-hydroquinone. Further, the rifamycin oxidase from Monocillium sp. has quite different properties as compared with other similar enzymes such as catechol oxidase, laccase, ascorbate 
oxidase, $o$-aminophenol oxidase and 3-hydroxyanthranilate oxidase, which utilize diphenols and related compounds as electron donors and oxygen as an electron acceptor [2]. The substrate specificity of rifamycin oxidase from Monocillium sp. was also different from that of the laccase from different sources. This enzyme oxidised hydroquinone and rifamycin B very rapidly, while laccase showed relatively low activity on those compounds [2]. Rifamycin oxidase from Monocillium sp. also oxidised rifamycin SV, 3-formyl rifamycin SV, pyrogallol and catechol. Resorcinol and the mannich derivative of rifamycin SV (3diethylaminomethyl rifamycin SV) were not attacked at all. The enzyme activity was neither inhibited by $\mathrm{Ag}^{+}$or $\mathrm{Hg}^{+2}$ nor activated by $\mathrm{Cu}^{+2}$. Other metal ions such as $\mathrm{Ca}^{+2}, \mathrm{Mg}^{+2}, \mathrm{Fe}^{+2}, \mathrm{Fe}^{+3}, \mathrm{Co}^{+2}, \mathrm{Mn}^{+2}, \mathrm{Zn}^{+2}$ and $\mathrm{Mo}^{+2}$ did not affect the enzyme activity [2]. EDTA caused no marked inhibition of the enzyme. The enzyme was neither a cupro-protein nor a flavo-protein; it did not contain any heme or non-heme ion nor any metals as co-factors [2]. Rifamycin oxidase from Monocillium sp. has $\mathrm{pH}$ and temperature optima of $\mathrm{pH} 7.8$ and $40{ }^{\circ} \mathrm{C}$, respectively.

The catalytic properties of partially purified rifamycin oxidase produced intracellularly by Humicola sp. were reported by Seong et al. [25]. The enzyme was most specific for rifamycin $\mathrm{B}$ among the various rifamycin derivatives tested [26]. The substrate specificity of the enzyme was investigated using various substrate analogues, including rifamycin B derivatives and other polyol compounds. $P$-hydroxyphenoxyacetic acid and $p$-hydroquinone which are corresponding structural analogues in the quinonoid moiety, caused a significant decrease in the enzyme activity compared to rifamycin B and rifamycin SV, respectively [25]. The enzyme showed highest catalytic activity on rifamycin B among the various substrates used. The $K_{m}$-value of this enzyme from Humicola sp. was found to be $0.05 \mathrm{mM}$ [25]. Substrate inhibition was observed at substrate concentrations above $2 \mathrm{mM}$. A pH of 7.8 and a temperature of $45^{\circ} \mathrm{C}$ were optimal for enzyme activity, catalytic activity was greatly reduced above this temperature. The rifamycin oxidase activity was strongly inhibited by $\mathrm{Fe}^{+2}$ and $\mathrm{Hg}^{+2}$, but not by other metal 
ions [25]. Presence of chelating agents such as EDTA did not affect the enzyme activity [25].

The optimum $\mathrm{pH}$ and temperature of rifamycin oxidase from Curvularia lunata are $\mathrm{pH} 6.5$ and $50{ }^{\circ} \mathrm{C}$, respectively [3]. The kinetic constants for the $C$. lunata enzyme have also been reported [26]. Under optimal conditions, MichaelisMenten type kinetics were observed [26]; the $K_{m}$ and $V_{\max }$ values, with rifamycin $B$ as substrate, were found to be $0.67 \mathrm{mM}$ and $11 \mathrm{IU} / \mathrm{mL}$, respectively [26]. No inhibition of enzyme activity was noted up to $10 \mathrm{mM}$ rifamycin $\mathrm{B}$ [26]. The activation and deactivation energies of the partially purified enzyme, calculated from Arrhenius plots, were 5.80 and $35.10 \mathrm{kcal} / \mathrm{mole}$ respectively [26]. The $C$. lunata rifamycin oxidase activity was inhibited by $\mathrm{Fe}^{+2}, \mathrm{Ag}^{+}$and $\mathrm{Hg}^{+2}$, but was not affected by the chelating agent, EDTA [26].

\section{Biotransformation with soluble enzymes}

Reports on biotransformation of rifamycin B to rifamycin S with soluble rifamycin oxidases are very limited. Intracellular rifamycin oxidases from Monocillium sp. and Humicola sp. were isolated from the cells and purified, but no systematic work was done to transform rifamycin B to $S$ with the soluble enzyme. Rifamycin B was used as a substrate simply to ascertain enzyme activity; rifamycin $\mathrm{S}$ did form in the reaction mixture.

Extracellular, soluble rifamycin oxidase from C. lunata was used by Banerjee et al. for the transformation of rifamycin B to $S$ [27]. The transformation conditions were optimized using partially purified rifamycin oxidase [27]. Transformation reactions were carried out at 28,37 and $50{ }^{\circ} \mathrm{C}$, with or without agitation. Incubation temperature, as well as the mixing rate, significantly affected the transformation rate [27]. Although at higher temperatures $\left(37\right.$ and $\left.50^{\circ} \mathrm{C}\right)$, the transformation time ( 2 hours) was less than at $28{ }^{\circ} \mathrm{C}$ ( 3 hours), for practical purposes, the lower temperature is preferred: Rifamycin oxidase has better thermostability at $28{ }^{\circ} \mathrm{C}$ and oxygen (a required reactant) is more soluble in aqueous solutions at lower temperatures. The transformation time in the absence of mixing was almost 50 hours at $28^{\circ} \mathrm{C}$. Optimal agitation speed was found to be 
$200 \mathrm{rpm}$. Different percentages $(2-8 \% \mathrm{v} / \mathrm{v})$ of enzyme solution were used, and $5 \%(\mathrm{v} / \mathrm{v})$ enzyme concentration was found to be optimal. Suitable aeration rate for the transformation, optimized in a $0.5 \mathrm{~L} \mathrm{MBR}$ bioreactor, was 1-1.25 vvm. Antifoam agent (polypropylene glycol) was added to suppress the foam. No adverse effect of the antifoam on enzyme activity was noted.

\section{Biotransformation with immobilized enzymes}

Rifamycin oxidase from $C$. lunata was immobilized on nylon fibres using glutaraldehyde as the crosslinking agent [28]. An activity of $18 \mathrm{IU} / \mathrm{g}$ fibres, with a binding efficiency of $37 \%$, was achieved. The immobilized enzyme showed an operational stability of 7-days and was protected against thermal inactivation. It exhibited a $K_{m(a p p)}$ of $2.0 \mathrm{mM}$. A polyacrylamide-based immobilization procedure has also been described for this enzyme [26]. Various percentages of acrylamide $(6-10 \% \mathrm{w} / \mathrm{v})$ were used for the immobilization; $10 \%(\mathrm{w} / \mathrm{v})$ gel strength was found to be optimal. Compared to free enzyme, the optimum $\mathrm{pH}(6.0-6.5)$ for the immobilized preparation shifted slightly to the acidic region, but the temperature optima were unaffected at $50{ }^{\circ} \mathrm{C}$. In biotransformation studies with the immobilized enzyme preparations, it took nearly 9 hours to complete the transformation whereas with soluble enzyme, with the same percentage of rifamycin $\mathrm{B}(1 \% \mathrm{w} / \mathrm{v})$, the reaction took 3 hours. The immobilized enzyme preparations were tested for reusability. Upon reuse, the beads acquired colour and after 3-4 uses, the transformation was additionally diffusionally limited. The time required for complete transformation increased with the number of use cycles. Transformation time for the fourth cycle was 10.5 hours, and in the sixth and seventh cycles the transformation time was 20 and 25 hours, respectively. Some adsorption of rifamycin on the beads was noted and it led to lower than expected recovery of rifamycin $\mathrm{S}$ after the transformation. So far, there are no reports of immobilization of soluble rifamycin oxidase from Monocillium or Humicola sp. 


\section{Biotransformation with whole cells in suspension}

As an enzyme source for industrial applications, whole cell preparations of Humicola sp. were tested by Seong et al. [25]. A time lag in the conversion time profile was observed in the initial stages of reaction with whole cells, but no such trend was noticed with acetone dried (delipidated) cells. Diffusional resistances to the substrates and products through the cell membrane, may have been responsible for the initial lag in conversion. Acetone treatment removes the major portion of lipids of the cell membrane making the cell more porous and removing any diffusional limitations. Also, the lag could be reduced by increasing the temperature. Enhanced mobility of membrane of whole cells at higher temperatures was a possible explanation for the reduced lag.

Substrate inhibition was observed with whole cells as well as with acetone treated cells when substrate concentration in the transformation reaction increased, but up to $4 \mathrm{mM}$ rifamycin $\mathrm{B}$ concentration there was no significant reduction in the initial rate of reaction [25]. Rifamycin $\mathrm{O}$ and rifamycin $\mathrm{S}$ are relatively hydrophobic and have an increased affinity to the cell membrane. This could cause their accumulation in the membrane resulting in further interference with the diffusion of substrate.

Han et al. clearly indicated the use of delipidated whole cells of Humicola sp. for attaining maximal conversion yield of rifamycin B to rifamycin S $[29,30]$. Banerjee reported the transformation of rifamycin $\mathrm{B}$ to rifamycin $\mathrm{S}$ using growing and resting cells of $C$. lunata [26]. The organism could grow in the presence of rifamycin B and simultaneously convert rifamycin B to rifamycin S [26]. With growing cells, rifamycin B was added at the time of inoculation in the medium. With $1 \%(\mathrm{w} / \mathrm{v})$ of rifamycin $\mathrm{B}$ in the medium, growth of the organism was reduced, but the transformation was completed within 20 hours of inoculation [26]. In other experiments, cells were grown up to the stationary phase and rifamycin $\mathrm{B}$ was added at different phases of growth. Twelve-hours grown cells in the culture broth took 16 -hours to complete the transformation, whereas with 24 hours grown cells it took only 4-hours. It took nearly 6-hours for 48-hours grown cells to complete the transformation. Seventy-two hours grown cells of $C$. lunata 
transformed only $10 \%$ of the added rifamycin B, and 96 and 120-hours grown cells did not transform any rifamycin B. Resting cells in both exponential and stationary phases could transform rifamycin $B$ to rifamycin $S$ and both could be reused for the transformation reaction. It took 3.6-hours to convert rifamycin $B$ $(1 \%, w / v)$ to rifamycin $S$ by 24 -hours grown, resting cells. The cells could be conveniently recycled up to ten-times. At the 10 th cycle, 18 -hours were taken to complete the transformation. Transformation of rifamycin B with growing and resting cells did not give stoichiometric yields; less than expected rifamycin $\mathrm{S}$ was obtained.

\section{Biotransformation with immobilized whole cells}

De-fatted whole cells of Humicola sp. with rifamycin oxidase activity have been immobilized by copolymerization with acrylamide for use in biotransformations of rifamycin [31]. The enzyme activity remaining after the immobilization step was $\sim 50 \%$ of the initial activity. The recovery of activity declined with increasing cell volume added into the original mixture [31]. This may have been due to increase in mass transfer resistances, or, to overpacking of the polyacrylamide gel matrix with cells. The optimal reaction $\mathrm{pH}$ for the immobilized, acetone de-fatted, cells was $\mathrm{pH} 7.8$, while the optimal temperature for both free and immobilized defatted whole cells was found to be $50^{\circ} \mathrm{C}$. Experiments were conducted at a lower temperature of $40^{\circ} \mathrm{C}$ to reduce enzyme inactivation. No appreciable activity loss occurred for the immobilized acetone de-fatted cells during one-month storage at $4{ }^{\circ} \mathrm{C}$ and $\mathrm{pH} 7.8$ [30]. The half life of the treated cells at $40^{\circ} \mathrm{C}$ and $\mathrm{pH} 8$ was $c a$. 8-days.

The Michaelis-Menten constants, $K_{m(a p p)}$, and the substrate inhibition constant, $K_{\text {in (app) }}$, of the immobilized, acetone de-fatted, cells were found to be 0.6 $\mathrm{mM}$ and $19.6 \mathrm{mM}$, respectively [31]. The $K_{m}$-value of the acetone de-fatted cells 
in free suspension was calculated at $0.3 \mathrm{mM}$. The simplest mechanism that could explain such a kinetic behaviour was suggested [32] to be the following:

$$
\begin{array}{cccc}
E+A \stackrel{K_{-1}}{\leftrightarrows} & E A & K_{2} & \\
& +A & \rightarrow & \\
& K_{a} \sqrt{K_{1} K_{-a}} & & \\
E A_{2} & \stackrel{K_{2}^{\prime}}{\rightarrow} & E A+X
\end{array}
$$

Using the steady state approximation in the above cited scheme, the overall rate of product formation may be shown to be

$$
v=\frac{\left(K_{2}+K_{2}^{\prime} K_{a}^{\prime}[A]\right)[E]_{0}[A]}{\frac{K_{-1}+K_{2}}{K_{1}}+\left(\frac{K_{2}^{\prime}}{K_{1} \cdot K_{a}^{\prime}}+1\right)[A]+K_{a}^{\prime}[A]^{2}}
$$

when $\mathrm{K}_{2}^{\prime} \neq 0$ and where $\mathrm{K}_{\mathrm{a}}^{\prime}-\frac{\mathrm{K}_{\mathrm{a}}}{\mathrm{K}_{-\mathrm{a}}+\mathrm{K}_{2}^{\prime}}$.

At sufficiently high substrate concentration, Equation (1) reduces to

$$
\mathrm{V}_{1 \mathrm{im}}-\mathrm{K}_{2}^{\prime}[\mathrm{E}]_{0} \text {. }
$$

It appears that for the immobilized, acetone de-fatted cell preparation $\mathrm{K}_{2}^{\prime}=0$ and, for acetone de-fatted, free cell preparation, the value of $\mathrm{K}_{2}^{\prime}$ is significant. The values of $V_{\max }$ and $V_{\text {lim }}$ for the acetone de-fatted cells were calculated to be 200 and $99 \mu$ mole $\bullet h^{-1} \mathrm{~g}^{-1}$, respectively. The $V_{\max }$ for the immobilized acetone defatted cells was $19.2 \mu$ mole $\mathrm{h}^{-1} \mathrm{~g}^{-1}$. A complete substrate inhibition was observed for the immobilized cells, whereas the enzyme activity was partially inhibited at high substrate concentration in freely suspended de-fatted cells.

In another preparation, the acetone de-fatted cells were immobilized on cellulose acetate [33]. The optimum $\mathrm{pH}$ and temperature of this catalyst were 
found to be $\mathrm{pH} 7.2$ and $50-55^{\circ} \mathrm{C}$, respectively. Compared to the free enzyme, the immobilized preparations were less sensitive to temperature and $\mathrm{pH}$ changes. Twenty percent of the enzyme activity was recovered when the treated cells were immobilized on $3 \mathrm{~mm}$ beads [33]. Recovery of the immobilized enzyme activity increased as the bead size became smaller. Mass transfer limitations were concluded to be the main reason for lower activity of the immobilized enzyme [33]. The optimal loading of the acetone treated cell powder for cellulose acetate beads was one gram powder in $50 \mathrm{~mL}$ acetone/dimethylsulfoxide $(3: 2 \mathrm{v} / \mathrm{v})$ mixture [33]. Higher enzyme loadings were not practical because of the precipitation of acetone treated cell powder during the immobilization process which caused problems with homogeneity of the catalyst. The physical strength of the cellulose acetate beads containing acetone de-fatted Humicola sp. cells was sufficient for use in packed bed reactors.

Besides the characterization of the enzyme rifamycin oxidase in free cells, whole cells and treated cells, Chung et al. did biotransformation studies in fluidized bed and rotating packed disc reactors [33]. A fluidized bed system with immobilized whole cells of Humicola sp. was used also by Lee et al. [34]. A linear relationship between the loading of the immobilized whole cells and conversion in both batch and continuous operations were found [34]; however, the conversion efficiency was higher in the batch mode for any given residence time [34]. Moreover, the aeration effect on the reaction rates in continuous operation was different from that in batch operation. Among the two reactor geometries used, the one which produced better mixing also gave $10 \%$ better yield.

For the biotransformation with immobilized whole cells in a rotating packed disc reactor (RPDR), Chung et al. found that the initial reaction rate and the total productivity were dependent upon the degree of submergence of the discs [35]. The optimal submergence was 0.5 ; the rotational speed of the disc did not affect the conversion very much. Higher conversions were attained with longer residence times; however, the productivity declined with increasing residence times. Higher volumetric productivities may be achieved if more enzyme is loaded in the immobilized enzyme beads, or, more discs are installed in the RPDR. A RPDR 
may be more amenable to plug flow operation than a fluidized bed reactor, which may increase the relative conversion efficiency in the RPDR. No reports of transformation of rifamycin B using immobilized whole cells or treated cells of Monocillium sp. or C. lunata have appeared so far.

\section{Conclusions}

The transformation of rifamycin $\mathrm{B}$ to rifamycin $\mathrm{S}$ can be successfully performed by rifamycin oxidase enzyme. Intracellular enzyme from Humicola sp. and Monocillium sp. may be used after extraction from the cells. Alternatively, delipidation of Humicola sp. may be employed to decrease the diffusional limitations in a process with the enzyme fixed within the cells. The transformation may also be achieved less expensively with the extracellular enzyme of $C$. lunata. The latter system has important processing advantages and either partially purified enzyme, or crude extracts of $C$. lunata can be used. Immobilized rifamycin oxidase preparations can also be employed with the advantages of greater stability, reusability and productivity. It is now clear that several biotransformation options may be used to prepare rifamycin $S$ from rifamycin $B$. In view of the importance of rifamycin $S$ as a key intermediate for the preparation of many semi-synthetic rifamycin derivatives of therapeutic value, further process improvements and scaleup considerations need to be investigated.

\section{Acknowledgements}

The financial support from the Council for Scientific and Industrial Research and the Department of Biotechnology, India, is gratefully acknowledged.

\section{References}

1. Vandamme, E.J. and Voets, J.P. (1974), Adv. Appl. Microbiol., 17, 311.

2. Han, M.H., Seong, B.L., Son, H.J. and Mheen, T.I. (1983), FEBS Lett., 151, 36.

3. Vohra, R.M., Banerjee, U.C., Das, S. and Dube, S. (1989), Biotechnol. Lett., 11, 851.

4. Oppolzer, W., Prelog, V. and Sensi, P. (1964), Experientia, 20, 336.

5. Lancini, G.C. (1986), "Ansamycins," In Biotechnology, Volume 4, (Rehm, H.J. and Reed, G., Editors), Verlag Chemie, Weinheim.

6. Leitich, J., Prelog, V. and Sensi, P. (1967), Experientia, 23, 505.

7. Lancini, G.C. and Sartori, G. (1976), J. Antibiot., 29, 466.

8. Lancini, G.C. and Sensi, P. (1967), In Proceedings of the 5th Intemational Congress on 
Chemotherapy, Volume 1, (Spitz, K.H. and Haschek, H., Editors), Verlag der wiener Medizinischen Akademie, p. 41.

9. Margalith, P. and Pagani, H. (1961), Appl. Microbiol., 9, 320.

10. Margalith, P. and Pagani, H. (1961), Appl. Microbiol., 9, 325.

11. Sensi, P., Ballota, R., Greco, A.M. and Gallo, G.G. (1961), Farmaco (Ed. Sci.), 16, 165.

12. Sensi, P. and Thiemann, J.E. (1967), Progress Ind. Microbiol., 6, 21.

13. Lancini, G.C., Thiemann, J.E., Sartori, G. and Sensi, P. (1967), Experientia, 23, 899.

14. Lancini, G.C., Gallo, G.G., Sartori, G. and Sensi, P. (1969), J. Antibiot., 22, 369.

15. Lancini, G.C., Hengheller, C. (1969), J. Antibiot., 22, 637.

16. White, R.J., Martenelli, E. and Lancini G.C. (1974), Proceedings Nat. Acad. Sci., USA, 71(8), 3260 .

17. Ghisalba, O., Traxler, P. and Nuesch, J. (1978), J. Antibiot., 31, 1124.

18. Schupp, T., Traxler, P. and Auden, J.A.L. (1981), J. Antibiot., 34, 965.

19. Ghisalba, O., Roos, R., Schuup, T. and Nuesch, J. (1981), J. Antibiot., 35, 74.

20. Seong, B.L., Son, H.J., Mheen, T.I. and Han, M.H. (1983), J. Antibiot., 36, 1402.

21. Vohra, R.M. and Dube, S. (1989), J. Chromatogr., 477, 463.

22. Kim, E.K., Choi, C.Y., Pask, J.M., Han, M.H. and Park, Y.H. (1984), J. Ferment. Technol., 62, 117.

23. Banerjee, U.C., Vohra, R.M., Jain, S.C. and Das, S (1992), J. Ferment. Technol. Bioeng., In press.

24. Banerjee, U.C. and Srivastava, J.P. (1992), J. Biotechnol., In press.

25. Seong, B.L., Som, H.J., Mheen, T.I., Park, Y.H. and Han, M.H. (1985), J. Ferment. Technol., 63, 515.

26. Banerjee, U.C. (1990), PhD Thesis, Panjab University, Chandigarh, India.

27. Banerjee, U.C. (1992), J. Biotechnol., In press.

28. Vohra, R.M. and Vyas, V.V. (1992), Biotechnol. Techniques, 6, 61.

29. Han, M.H., Mheen, T.I., Seong, B.L. and Som, H.J. (1984), U.S. Patent 4,431, 735.

30. Han, M.H., Mheen, T.I., Seong, B.L. and Som, H.J. (1983), Japan Kokai 58,138,390.

31. Lee, G.M., Choi, C.Y., Park, J.M. and Han, M.H. (1984), Biotechnol. Lett., 6, 143.

32. Laidler, K.J. and Bunting, P.S. (1973), The Chemical Kinetics of Enzyme Action, 2nd edition, Clarendon Press (Oxford).

33. Chung, B.H., Chang, H.N. and Han, M.H. (1985), Korean J. Appl. Microbiol. Bioeng., 13(2), 115.

34. Lee, G.M., Choi, C.Y., Park, J.M. and Han, M.H. (1985), J. Chem. Technol. Biotechnol., 35B, 3.

35. Chung, B.H., Chang, H.N. and Han, M.H. (1986), J. Ferment. Technol, 64, 343. 